\title{
Verbal and Spatial Processing Efficiency in 32 Children with Sex Chromosome Abnormalities
}

\author{
BRUCE G. BENDER, MARY G. LINDEN, AND ARTHUR ROBINSON \\ National Jewish Center for Immunology and Respiratory Medicine and University of Colorado School of \\ Medicine, Denver, Colorado 80206
}

\begin{abstract}
Spatial and linguistic processing efficiency was evaluated in sixty 8 - to 18 -yr-old children, including thirteen 47,XXY boys, eleven 47,XXX girls, six girls with $45, X$, two girls with $46, X, X q-$, and 28 chromosomally normal controls. Results indicated that the 47,XXX girls performed significantly below controls on all four cognitive tests. Scores of the $X$ monosomy group were reduced on both spatial tests, one requiring rapid information processing and one without time requirements, which is consistent with previous reports of spatial thinking deficits in these propositae. The X monosomy girls also had difficulty completing the high efficiency but not the low efficiency verbal tests. Scores in the 47, XXY group did not differ from controls on either spatial test or on the low efficiency verbal task. When required to rapidly access verbal information from memory, however, the performance of these boys was significantly impaired. This finding confirms earlier reports of impeded verbal fluency in these propositi. Alteration in capacity to rapidly process information appears to distinguish $47, X X Y$ boys and $X$ monosomy girls from their chromosomally normal peers, and suggests that adaptations in their educational setting should be introduced to allow additional time to learn and complete work. (Pediatr Res 25:577-579)
\end{abstract}

\section{Abbreviation}

SCA, sex chromosome abnormalities

Studies of individuals with SCA over the last 25 y have attempted to define and correlate karyotype-specific psychologic phenotypes. Investigations of cognitive and neuropsychologic components of these phenotypes have outnumbered other psychologic studies and provided considerable information about the intellectual functions of individuals with abnormal amounts of sex chromatin. Women with a $45, \mathrm{X}$ karyotype, for example, are known to have below average ability for spatial thinking (1), and 47,XXY men to have impaired language skills (2). Women with a $47, \mathrm{XXX}$ karyotype, in contrast, are generally found to have a global intellectual deficit, including both spatial and linguistic skills (3).

In the past decade, psychologic studies have attempted to pinpoint specific cognitive processes that are under the direct

Received November 17, 1988; accepted January 12, 1989.

Correspondence and reprints Arthur Robinson, M.D., National Jewish Center for Immunology and Respiratory Medicine, 1400 Jackson St., Denver, CO 80206.

Supported, in part, by United States Public Health Services Grant 5R01HD 10032, Grant RR-69 from the General Clinical Research Centers Program of the Division of Research Resources, National Institutes of Health, and The Genetic Foundation. influence of SCA and that are associated with and may underlie these spatial and language deficits of $45, \mathrm{X}$ and $47, \mathrm{XXY}$ propositi. Thus, $45, \mathrm{X}$ females have been found to have difficulty with design copying (4), mental rotation (5), and spatial memory (6), whereas 47,XXY males have difficulty with expressive language (7), reading (8), and auditory memory (9).

Common to both $45, \mathrm{X}$ and $47, \mathrm{XXY}$ karyotype groups is the finding of significantly reduced speed during cognitive tasks. Slowed processing rates have been reported for $45, \mathrm{X}$ subjects during spatial problem solving (5) and for 47,XXY subjects during linguistic tasks $(8,10)$. However, it is unclear whether $45, \mathrm{X}$ subjects experience speed-of-processing deficits exclusive to spatial tasks, whereas $47, \mathrm{XXY}$ subjects demonstrate speed-ofprocessing deficits exclusive to linguistic tasks, or whether both groups exhibit slowed cognitive efficiency on both types of tasks.

Processing speed in 47, XXX women has not often been studied, presumably because of their usual nonspecific, global intellectual deficit. One study reported fast responses but low accuracy for a group of eight 47, XXX girls during a sentence comprehension task (11). In the absence of comparative information regarding spatial versus linguistic speed for any of the three karyotype groups $(45, \mathrm{X}, 47, \mathrm{XXY}, 47, \mathrm{XXX})$ the question of karyotypespecific processing speed deficiency remains unanswered and, consequently, is the focus of this study.

\section{MATERIALS AND METHODS}

Subjects. A total of 60 children, ages 8 to $18 \mathrm{y}$, were included in this study (Table 1). A total of 32 SCA propositi were identified through the screening of amniotic membranes from 40000 consecutive newborns at two Denver hospitals, and therefore this sample was unselected (12). When discrepancies between laboratory finding and phenotypic sex occurred, chromosomes were analyzed. Included were 1347 , XXY boys, 1147 , XXX girls, six girls with $45, X$, and two girls with $46, X, X q-$. All of the girls in the latter group have some of the characteristics of Turner syndrome, including short stature, gonadal dysgenesis, and triangular facies. The control group included 28 children, 14 males and 14 females, who were siblings of various propositi, with no more than one control obtained from any family.

Testing procedures. To measure efficiency for verbal and spatial thinking, it was necessary to choose tasks meeting two criteria. First, the selected tasks needed to evaluate skills that required primarily spatial or language-based thought to measure the two skill areas separately. Second, timed and untimed tests were needed to allow for comparison of verbal and spatial skills with and without speed demands. Using these criteria, the following four tasks were selected.

1) Time independent verbal task. The vocabulary subtest from the Wechsler intelligence scale for children-revised (13) measures word knowledge by requiring the subject to produce a definition of a series of vocabulary words. Although it is a measure of 
expressive language requiring retrieval of verbal information, there are no time limits.

2) Time dependent verbal task. The Thurstone word fluency test (14) requires the subject to create a list of words beginning with the letter " $\mathrm{s}$ " within a 5 -min period. The resulting quotient score is dependent on the speed with which words can be retrieved within the time limit.

3) Time independent spatial task. The untimed version of the spatial relations test from the primary mental abilities battery (14) (PMA spatial relations test) requires the subject to mentally rotate two-dimensional geometric shapes.

4) Time dependent spatial task. The spatial relations test from the Woodcock-Johnson psychoeducational battery (15) (WJ spatial relations test) is similar to the PMA spatial relations test in its requirement of mental rotation of two dimensional geometric shapes. However, the score from the WJ spatial relations test is dependent upon the number of figures correctly rotated within the 3-min time limit.

\section{RESULTS}

All scores were converted to a single scale with mean $=100$ and $\mathrm{SD}=15$. For each of the four measures, paired $t$ tests were conducted between the control group and each group of propositi $(47, X X Y, 45, X$ and $47, X X X)$.

Spatial test results indicated that the $45, X$ group and the $47, \mathrm{XXX}$ group performed significantly below the control group on both the PMA spatial relations test $(p=0.004$ and 0.003 , respectively) and the WJ spatial relations test $(p=0.001$ and 0.003 , respectively), whereas the $47, \mathrm{XXY}$ group was not significantly different from controls on either measure of spatial thinking (Fig. 1). Thus, the 45,X and 47,XXX girls demonstrated deficits of spatial thinking regardless of whether rapid or slow processing of the spatial information was required.

Results from the two verbal tests indicated that the $47, \mathrm{XXY}$

Table 1. Subjects

\begin{tabular}{lrl}
\hline \multicolumn{1}{c}{ Group } & $n$ & Mean age \\
\hline $47, \mathrm{XXY}$ & 13 & $12 \mathrm{y} 4 \mathrm{mo}$ \\
$47, \mathrm{XXX}$ & 11 & $15 \mathrm{y} 2 \mathrm{mo}$ \\
45,X and 46,X,Xq-* & 8 & $11 \mathrm{y} 9 \mathrm{mo}$ \\
Controls & 28 & 12 y 7 mo \\
\hline
\end{tabular}

* 46,X,del(X)(pter q 13:)

46,X,del(X)(pter q21.1:).

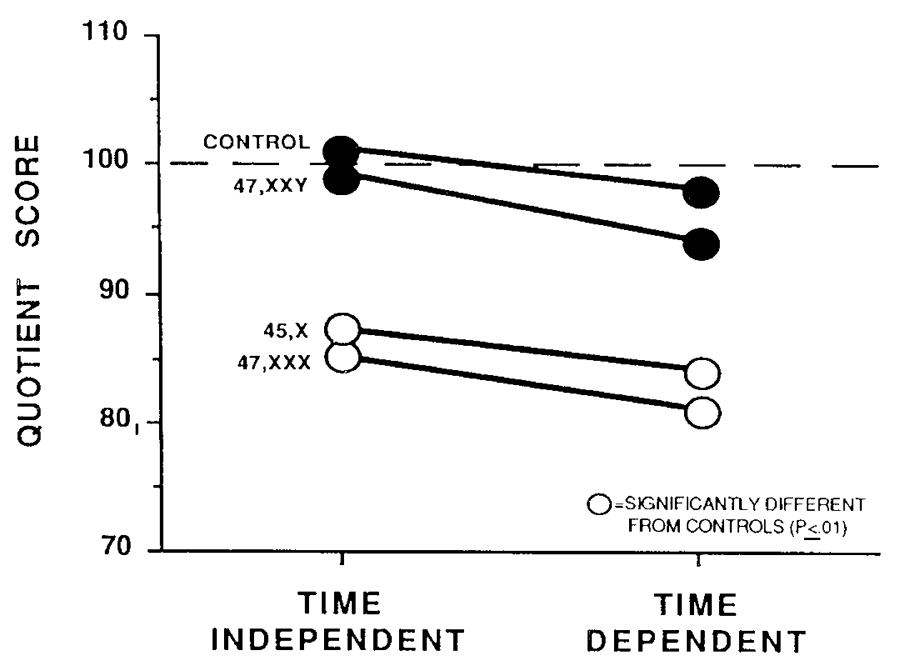

TASK

Fig. 1. Spatial processing. boys and 45, X girls were significantly less proficient than controls only on the test requiring rapid retrieval of verbal information ( $p=0.002$ and 0.005 , respectively) (Fig. 2). Their vocabulary scores were less than those of controls but were not significantly lower. In the case of 47,XXX girls, both the time-dependent and time-independent scores were lower than those of controls ( $p=$ 0.005 and 0.010 , respectively). However, the data trends were opposite of those of the other three groups, i.e. the $47, \mathrm{XXX}$ group appeared to perform better on the word fluency test than on the vocabulary test.

\section{DISCUSSION}

The language processing deficit in this group of $47, \mathrm{XXY}$ boys was most pronounced when required to rapidly recall selected verbal information. This finding of slow retrieval is consistent with our own previous findings of reduced speed of auditory processing and dyslexia characterized by difficulty accessing longterm memory while reading (8). In a recent comprehensive report of language skills in $1447, \mathrm{XXY}$ boys, Graham et al. (10) found that 11 had marked difficulty sequencing rapidly presented nonverbal tones. They concluded that this deficit accounts in part for observed language and reading problems and supports the generally held assumption of left-hemisphere dysfunction in 47, XXY propositi (10).

In contrast to the unimpaired spatial processing of the $47, \mathrm{XXY}$ boys, the depressed spatial thinking in the group of $45, \mathrm{X}$ girls is consistent with their identified "visuospatial" deficit first documented 26 y ago (1). Their difficulty processing two-dimensional visual information was striking and was present with or without time demands. Also notable is the finding of impaired ability to rapidly access verbal information in the $45, X$ group similar to that seen in the $47, \mathrm{XXY}$ group. Although they were able to complete time-independent verbal tasks without impairment, their performance on the time-dependent task was significantly depressed. Although small sample sizes necessitate cautious generalizations, other investigators have found reduced speed among $45, X$ subjects performing verbal tasks. Rovet and Netley (5) reported slower response rates among Turner syndrome girls on both spatial transformation and sentence identification tasks. Waber (6) documented significantly reduced scores on a word fluency test in a group of 11 Turner syndrome adolescents and adults. Together with other reports of verbal memory impairment $(16,17)$, these findings indicate that $45, \mathrm{X}$ girls experience a disruption of cognitive processes not exclusive to spatial thinking. Furthermore, their difficulties do not suggest, as once believed, localized right hemisphere dysfunction. Comprehensive neuropsychologic evaluations of Turner syndrome patients con-

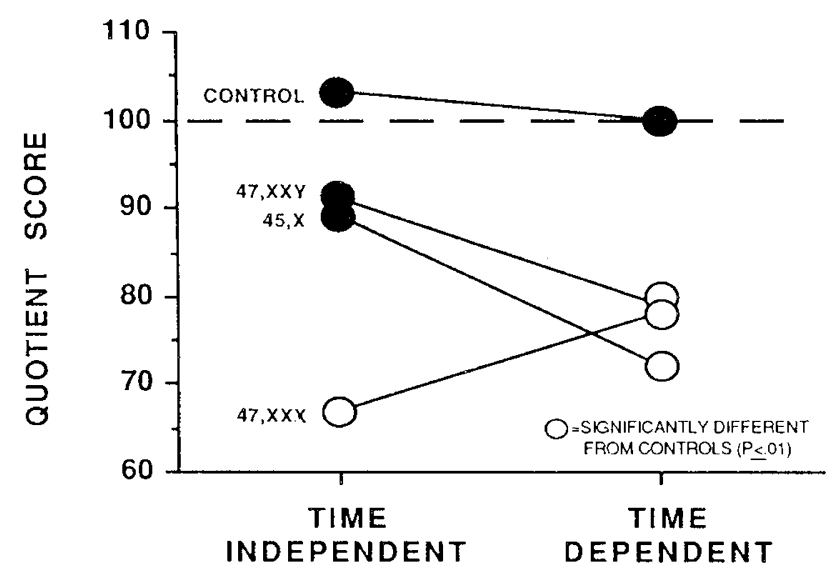

TASK

Fig. 2. Verbal processing. 
firm the conclusion that their intellectual difficulties cannot be traced to a specific right hemisphere site (18). Rovet and Netley (5) have suggested that the right and left hemispheres of $45, \mathrm{X}$ propositae are organized differently from those of other females due to changes in neural growth rates. Specifically, spatial information is processed by both hemispheres, and the right hemisphere does not develop its usual capacity superior to the left hemisphere's capacity for spatial thought.

Scores of the 47,XXX girls were below those of controls on all four verbal and spatial tasks. Other investigations have similarly reported global intellectual deficits among 47, XXX girls requiring educational intervention in a variety of subjects (19-21). Of particular interest here was the finding of apparent superior performance on the word fluency test compared to the vocabulary test. This suggests that 47,XXX girls can perform automated verbal tasks better than tasks requiring greater verbal comprehension and expression, a pattern opposite to that of the $45, \mathrm{X}$ girls and $47, X X Y$ boys. Other evidence that triple $X$ girls may in certain circumstances be capable of relatively rapid processing emerged in a study by Rovet and Netley (11). They presented a group of 11 propositae with spatial rotation and sentence identification tasks and found that the triple $\mathrm{X}$ children performed both types of tasks more quickly and less accurately than chromosomally normal controls.

Alteration in the capacity to rapidly process information appears to distinguish SCA children from chromosomally normal controls. 45, X and 47, XXY children in this study demonstrated relative verbal mastery that diminished significantly when required to rapidly access verbal information, whereas $47, \mathrm{XXX}$ children exhibited an opposite pattern. These results indicate that some SCA children may be helped to achieve greater success in school if provided with extra time to understand and learn new information, to complete assignments, and to take tests.

Continued efforts to isolate a single component of cognition directly influenced by SCA may succeed in further determining whether other observed SCA deficits are associated with processing speed dysfunction, or whether the latter is part of a larger cognitive system affected at multiple levels. Attempts to reduce SCA-related deficits to pure, homogeneous psychologic phenotypes can be only partially successful because considerable phenotypic variability continues to characterize all SCA groups (8, 22). Karyotypic homogeneity is not equivalent to phenotypic homogeneity (23). Although intergroup characteristics will teach us much about the influence of various SCA, intragroup differences continue to remind us that the individuality of each propositus mediates the developmental impact of the SCA.
REFERENCES

1. Shaffer J 1962 A specific cognitive deficit observed in gonadal aplasia (Turner's syndrome). J Clin Psychol 18:403-406

2. Annell AL, Gustavson KH, Tenstam J 1970 Symptomatology in schoolboys with positive sex chromatin (the Klinefelter syndrome). Acta Psychiatr Scand 46:71-80

3. Linden M, Bender BG, Harmon RJ, Mrazek DA, Robinson A 1987 47, XXX: what is the prognosis? Pediatrics 82:619-630

4. Bender B, Puck M, Salbenblatt J, Robinson A 1984 Cognitive development of unselected girls with $X$ and partial $X$ monosomy. Pediatrics 73:175-182

5. Rovet J, Netley C 1982 Processing deficits in Turner's syndrome. Dev Psychol 18:77-94

6. Waber D 1979 Neuropsychological aspects of Turner's syndrome. Dev Med Child Neurol 21:58-70

7. Stewart DA, Netley CT, Bailey JD, Haka-Ikse K, Platt J, Holland W, Cripps M 1979 Growth and development of children with X and Y chromosome aneuploidy: a prospective study. Birth Defects 15:75-114

8. Bender B, Puck M, Salbenblatt J, Robinson A 1986 Dyslexia in 47, XXY boys identified at birth. Behav Genet 16:343-354

9. Graham JM, Bashir AS, Walzer S, Stark RE, Gerald PS 1981 Communication skills among unselected XXY boys. Pediatr Res 15:562

0. Graham JM, Bashir AS, Stark RE, Silbert A, Walzer S 1988 Oral and written language abilities of XXY boys: Implications for anticipatory guidance. Pediatrics 81:795-806

11. Rovet J, Netley C 1983 The triple X syndrome in childhood: Recent empirical findings. Child Dev 54:831-845

12. Robinson A, Puck T 1967 Studies on chromosomal nondisjunction in man. II. Am J Hum Genet 19:112-129

13. Wechsler D 1974 Wechsler Intelligence Scale for Children-Revised. Psychological Corporation, New York

4. Thurstone TG 1962 Primary Mental Abilities Test. Science Research Associates, Chicago

15. Woodcock RW, Johnson MB 1977 Woodcock-Johnson Psycho-Educational Battery. Teaching Resources, Hingham, MA

16. Pennington $B F$, Heaton RK, Karzmark P, Pendleton MG, Lehman R, Shucard DW 1985 The neuropsychological phenotype in Turner syndrome. Cortex 21:391-404

17. McGlone J 1985 Can spatial deficits in Turner's syndrome be explained by focal CNS dysfunction or atypical speech lateralization? J Clin Exp Neuropsychol 7:375-394

18. Money J 1973 Turner's syndrome and parietal lobe functions. Cortex 9:385393

19. Stewart DA, Bailey JD, Netley CT, Rovet J, Park E, Cripps M, Curtis JA 1982 Growth and development of children with $X$ and $Y$ chromosome aneuploidy from infancy to pubertal age: the Toronto study. Birth Defects 18:99-154

20. Ratcliffe SG, Tierney I, Nshaho J, Smith L, Springbett A, Callan S 1982 The Edinburgh study of growth and development of children with sex chromosomal abnormalities. Birth Defects 18:41-60

21. Pennington BF, Bender B, Puck M, Salbenblatt J, Robinson A 1982 Learning disabilities in children with sex chromosome anomalies. Child Dev 53:11821192

22. Bender B, Berch D 1987 Sex chromosome abnormalities: Studies of genetic influences on behavior. Integr Psychiatry 5:171-178

23. Decker S, Bender BG 1988 Converging evidence for multiple genetic forms of reading disability. Brain Lang 33:197-215 